\title{
A mudança da ordem dos constituintes adjetivo e substantivo na língua catalã: uma análise diacrônica
}

\section{Bruno Fernandes Zenóbio de Lima Universidade Federal de Minas Gerais}

\section{Abstract}

In face of the quantitative analysis of sintagma nominal (SN) of the Catalan language, giving relevance to the relations between the constituents, adjective and substantive, and, through a corpus composed of texts dated from the 13th, 14th, 15th, and 20th centuries, I noted the change of word order of the constituents A (adjective) and $\mathrm{N}$ (substantive), to $\mathrm{AN}>\mathrm{NA}$. In other words, the old order, the anteposition of A to $\mathrm{N}$, gives place to a more recent form, the posposition of $\mathrm{A}$ in relation to $\mathrm{N}$. I verified that certain inherent semantic features act as determinative factors of the order of these constituents, the adjectives and substantives. 


\section{APRESENTAÇÃO}

$\mathrm{E}$ ste artigo consiste, especificamente, na apresentação dos resultados de uma análise diacrônica do sintagma nominal (SN) da língua catalã, dando relevância às relações entre os constituintes adjetivo e substantivo. Para tal, foram realizados quatro recortes através de um corpus composto por textos em prosa datados do século XIII, XIV, XV e XX. Esse corpus, a meu ver, possibilitou uma diferença temporal que tornou possível a identificação da mudança de posicionamento de A (adjetivo) e N (substantivo) dentro do sintagma nominal catalão nos períodos históricos supracitados.

O ponto central do trabalho é a formulação de uma hipótese que explique como ocorreu a mudança na colocação dos constituintes A e N no SN catalão, identificada pela análise quantitativa, passando das duas ordens usuais no Indo-Europeu, a uma ordem predominante (posposição de A), ou seja, NA (posposição de A a N) AN (anteposição de A a N) > NA, estabelecendo os fatores que estariam motivando, ou não, a mudança.

Primeiramente, apresento os modelos teóricos que elucidam questões referentes à mudança $\mathrm{AN}>\mathrm{NA}$, e às relações semânticas existentes na associação de substantivos e de adjetivos, considerando argumentos teóricos capazes de explicar a mudança AN > NA em termos de um realinhamento tipológico SOV (latim) > SVO (catalão). Na seção seguinte, "Análise Quantitativa”, apresento os resultados quantitativos das ocorrências dos SN analisados, fazendo alguns comentários relativos à significância desses dados quantitativos para a análise lingüistica. Finalmente, são apresentadas análises conclusivas e tendências gerais da ordenação do SN catalão. 


\section{MODELO TEÓRICO}

O modelo teórico utilizado para a descrição histórica do sintagma nominal, especificamente os itens adjetivo e substantivo, foi o da tipologia de mudança da ordem vocabular, desenvolvida a partir dos pressupostos teóricos postulados por Greenberg (1961).

Greenberg analisou uma amostra que perfaz um total de 30 línguas, dentre elas línguas românicas, eslavas, germânicas, e outras não Indo-Européias. Nesse sentido, as línguas do mundo foram agrupadas considerando-se os seguintes parâmetros: a) Sujeito (S), Verbo (V) e Objeto (O); b) Preposições (Pr) e Posposições (Po); c) Nome (N) e Adjetivo (A). Greenberg também considerou aspectos geográficos e genéticos em sua amostragem.

No que diz respeito ao Proto-Indo-Europeu, estudos apontamno como tipologicamente SOV, ao menos em algum período de sua evolução, enquanto que o Latim não se enquadra, de maneira precisa, em nenhum dos padrões, pois possuía tanto traços SOV quanto SVO.

Ao analisar as ocorrências e suas relações com certos parâmetros, Greenberg pôde postular universais regulares que sintetizavam tendências gerais das línguas analisadas. O autor concluiu, por exemplo, que as línguas SOV têm posposições e ordenam o Adjetivo antes do Nome (SOV/ PO/ AN). Do total das trinta línguas analisadas, 6 ou $20 \%$ delas são (SOV/ Po/ AN), 5 ou 17\% delas são (SOV/ Po/ NA). No que se refere às línguas tipo SOV, que é o mais freqüente das onze combinações possíveis, a correlação mais forte é (SVO/ Pr/ NA), embora também sejam possíveis, segundo Greenberg, as seguintes combinações (SOV/ $\mathrm{Pr} / \mathrm{AN}),(\mathrm{SOV} / \mathrm{Po} / \mathrm{AN})$, e (SVO/ Po/ NA). Greenberg também analisou a ordem de colocação do nome em suas relações com: a) o Genitivo, (GN/NG); b) os Demonstrativos, (DN/ND); c) a Oração Relativa, (N Orel / Orel N); d) o Numeral (Num N/N Num).

Dentro dessa perspectiva, uma língua tem consistência se esses parâmetros funcionam harmonicamente entre si, ordenando modificadores e modificados. Desse modo, cada tipo lingüístico 
deveria pertencer a uma língua, o que, entretanto, não acontece, como é o caso do Inglês, que apesar de ser SVO/Pr, posiciona os Adjetivos antes do Nome. Inconsistências lingüísticas, como as encontradas no Inglês, apontam uma mudança de um tipo ideal para outro, tendo, necessariamente, essa mudança uma direção.

Em geral, as línguas românicas foram classificadas como SVO/ $\mathrm{Pr} / \mathrm{NG} / \mathrm{NA}$, conforme Greenberg (1966:109), apesar de várias inconsistências que essas línguas apresentam, como por exemplo, a ordem AN, a ordem GN, e a existência de pronomes-objeto proclíticos como em "Eu a lavei", que se referem à ordem SOV. Entretanto, mesmo diante dessas inconsistências, são previstos períodos intermediários entre os tipos ideais que demonstrariam a existência de uma língua tipo TVX (=Tópico, Verbo, Objeto), e que corresponderia a um tipo transitório de SOV para SVO.

\subsection{A tipologia românica SOV/Pr/NA}

Passo a analisar mais especificamente a tipologia lingüística SVO, que compreende a do catalão medieval e a do catalão contemporâneo. O trabalho de Greenberg que serve de referência para a descrição do tipo SVO é o intitulado "Some universals of grammar with particular reference to the order of meaningful elements", publicado em 1966.

Segundo Greenberg, os tipos lingüísticos são unidades que estão relacionadas a um conjunto de características sintáticas que funcionam como implicações universais. Veja-se o quadro 1 com os dados de Greenberg (1966: 85): 
Quadro 1

Descrição dos universais lingüísticos das

30 línguas analisadas por Greenberg (1966: 85).

\begin{tabular}{|cccc|}
\hline & VSO & SVO & SOV \\
NA & 6 & 8 & 5 \\
AN & 0 & 5 & 6 \\
& & & \\
& Pr & Po & \\
NA & 12 & 7 & \\
AN & 4 & 7 & \\
\hline
\end{tabular}

Os dados acima fazem uma descrição das trinta línguas analisadas por Greenberg em relação à posição do adjetivo e do nome, considerando-se aspectos como a existência de posposições (Po) e de preposições (Pr), nessas línguas.

Pode-se perceber que o tipo mais comum é o SVO, que corresponde a 13 línguas, 43\% do total das línguas analisadas. Os dados mostram que a tendência das línguas preposicionadas é de pospor adjetivos a substantivos, como é o caso dos romances formados a partir do latim, que perderam as declinações e os casos latinos. Entretanto, as línguas SVO, embora sejam predominantemente NA, admitem a anteposição de A em relação a N, como afirma Greenberg (1966: 87):

Universal 19: Quando a regra geral é que o adjetivo descritivo segue [o substantivo], pode haver uma minoria de adjetivos que normalmente precedem, mas quando a regra geral é que os adjetivos descritivos precedem, não há nenhuma exceção. ${ }^{1}$

Desse modo, nas línguas do tipo SVO, como o catalão, existem duas ordens possíveis em relação a N e a A: AN NA. Como descrito por Waugh (1977), existem motivações lingüísticas específicas que podem levar adjetivos a se anteporem ou posporem ao nome. 
Outras considerações podem ser feitas no intuito de se identificar o catalão como SVO. Vejamos o quadro 2, que descreve os tipos lingüísticos em relação à prefixação e sufixação:

Quadro 2

Descrição dos universais lingüísticos das 30 línguas analisadas por Greenberg (1966: 85) em relação aos aspectos da prefixação e da sufixação

\begin{tabular}{|lccc|}
\hline & VSO & SVO & SOV \\
Exclusivamente prefixação & 0 & 1 & 0 \\
Exclusivamente sufixação & 0 & 2 & 10 \\
Ambas & 6 & 10 & 1 \\
& $\mathrm{Pr}$ & Po & \\
& & & \\
Exclusivamente prefixação & 1 & 0 & \\
Exclusivamente sufixação & 0 & 12 & \\
Ambas & 15 & 2 & \\
\hline
\end{tabular}

O quadro 2 indica que o tipo lingüístico SVO, que corresponde ao catalão, apresenta a existência de prefixação e sufixação. Outra consideração que também pode ser feita é que nas línguas preposicionadas se verificam processos de prefixação e sufixação, o que ocorre com o catalão, que é uma língua em que pode ser observado o emprego de preposições, enquadrando-se no parâmetro SVO.

Desse modo, o modelo da tipologia de mudança da ordem vocabular, proposto por Greenberg (1966), deve, entretanto, apoiarse necessariamente numa análise de corpora que o corrobore, e que forneça-lhe elementos objetivos. Nesse sentido, procedi a uma análise quantitativa de caráter variacionista, objetivando levantar informações relativas à freqüência e ao peso relativo dos fatores escolhidos e, finalmente, por meio desses dados, corroborar a tese da mudança da ordem dos constituintes adjetivo e substantivo no corpus catalão analisado. 


\section{ANÁLISE QUANTITATIVA}

Para a análise do corpus foram estabelecidos fatores que, de maneira geral, tiveram como propósito fundamental descrever e explicitar: a) relações semânticas existentes entre os substantivos e os adjetivos; b) relações entre a classe morfológica dos adjetivos e a posição; c) traços semânticos específicos das palavras. Desses fatores, considerei primordialmente suas relações no que se refere à ordem variável (AN NA).

$\mathrm{Na}$ análise das ocorrências do corpus composto de sintagmas nominais da língua catalã foram separadas duas áreas de incidência dos critérios: sobre o adjetivo e o substantivo. Os grupos de fatores utilizados na análise quantitativa são os seguintes: adjetivos: a) [qualificativo] e [restritivo]; b) expressões-gatilho, como os adjetivos Bon, Gran, Noble, Notable e Bel, [gatilho] e [não-gatilho]; c) [derivado] e [primitivo]; substantivos: a) [animado] e [inanimado]; b) [concreto] e [abstrato].

Foram registradas um total de 1535 ocorrências, distribuídas entre os quatro períodos analisados, séculos XIII, XIV, XV e XX. Desse total, 829 ocorrências, $54 \%$ do total, são de $\mathrm{SN}$ com adjetivos antepostos, e o restante, 706 ocorrências, 46\% do total, são de adjetivos pospostos. Veja-se a tabela 1 abaixo, que descreve a distribuição total das ocorrências de SN dos períodos analisados em relação à posição dos adjetivos dentro do $\mathrm{SN}$ :

Tabela 1: Distribuição total das ocorrências segundo o período e a posição.

\begin{tabular}{c|c|c|c|c|c}
\hline Período & AN & $\%$ & NA & $\%$ & Total \\
\hline Século XIII & 230 & 68 & 107 & 32 & 337 \\
Século XIV & 275 & 69 & 123 & 31 & 398 \\
Século XV & 275 & 68 & 127 & 32 & 402 \\
Século XX & 49 & 12 & 349 & 88 & 398 \\
\hline Total & $\mathbf{8 2 9}$ & 54 & $\mathbf{7 0 6}$ & 46 & $\mathbf{1 5 3 5}$ \\
\hline
\end{tabular}


No que diz respeito aos itens gatilho, o lugar deles é preferencialmente a anteposição, sendo a média total de anteposição de gatilhos $92 \%$ em todos os períodos analisados.

A seguir apresento, primeiramente, a tabela 2 que contém os valores e os parâmetros das melhores rodadas. Na tabela 3 apresento os resultados da análise de peso relativo da classe dos itens gatilho, que indicam, em geral, o favorecimento da sua anteposição, sendo que, no século XX, essa classe tem um peso de 0,065, o que favorece muito a anteposição de itens gatilho. O item lexical grané o que mais ocorre dentre os itens gatilho, seja na anteposição, seja na posposição, e o que menos recorre, ou seja, menos ocorre com os mesmos substantivos. Veja-se respectivamente as tabelas 2 e 3:

Tabela 2: Parâmetros e valores do peso relativo de cada rodada por século.

\begin{tabular}{lcccc|c|c|c}
\hline Período & Melhor Rodada & Células & Significância & Convergência & Input & Log \\
\hline Século XIII & Rodada \# 11 & 9 & 0,008 & 7 & 0,290 & $-160,058$ \\
Século XIV & Rodada \# 7 & 8 & 0,001 & 6 & 0,159 & $-165,637$ \\
Século XV & Rodada \# 11 & 11 & 0,001 & 7 & 0,739 & $-189,891$ \\
Século XX & Rodada \# 7 & 8 & 0,027 & 7 & 0,947 & $-99,709$ \\
\hline
\end{tabular}

Tabela 3: Distribuição da freqüência e do peso relativo dos fatores adjetivos gatilhos/não-gatilhos por século.

\begin{tabular}{lccccccccccccc}
\hline Séc. & Gatilhos & AN & $\%$ & NA & $\%$ & Peso & Adjetivos & AN & $\%$ & NA & $\%$ & Peso & Total \\
\hline XIII & $\mathbf{1 1 1}$ & 100 & 90 & 11 & 10 & 0,333 & $\mathbf{2 2 6}$ & 130 & 57 & 96 & 43 & 0,584, & $\mathbf{3 3 7}$ \\
XIV & $\mathbf{1 6 2}$ & 158 & 98 & 3 & 2 & - & $\mathbf{2 3 6}$ & 116 & 49 & 120 & 51 & - & $\mathbf{3 9 8}$ \\
XV & $\mathbf{1 6 9}$ & 151 & 88 & 18 & 12 & 0,333 & $\mathbf{2 3 3}$ & 124 & 53 & 109 & 47 & 0,619 & $\mathbf{4 0 2}$ \\
XX & $\mathbf{1 1}$ & 8 & 73 & 3 & 27 & 0,065 & $\mathbf{3 8 7}$ & 41 & 11 & 346 & 89 & 0,519 & $\mathbf{3 9 8}$ \\
\hline Total & $\mathbf{4 5 3}$ & 417 & 92 & 35 & 8 & - & $\mathbf{1 0 8 2}$ & 411 & 38 & 671 & 62 & - & $\mathbf{1 5 3 5}$ \\
\hline
\end{tabular}

A liderança dos itens gatilho corrobora a análise de Cohen (1990), ao afirmar que certos adjetivos com traços semânticos específicos desempenham um papel mais relevante na mudança da ordem AN > NA, do que outros tipos. 
Em relação aos adjetivos com traço [qualificativo] e [restritivo] ficou clara a predominância dos qualificativos na anteposição até o século XV. Entretanto, no século XX, os qualificativos passam a ser preferencialmente pospostos, existindo a variação AN NA, já que, nesse período, 37\% dos adjetivos qualificativos são antepostos, e 63\% são pospostos, sendo que o número total de qualificativos nesse século é apenas 108, 27\% do total, e as 290 ocorrências restantes são de restritivos, que correspondem a $73 \%$ do total. Em termos de peso relativo, os qualificativos desfavorecem a posposição, ainda com mais intensidade no século XX, em 0,109. Com relação aos restritivos, pode ser dito que, em todos os períodos analisados, o lugar de maior ocorrência deles é a posposição. Foram observados, em média, 93\% de adjetivos restritivos pospostos aos substantivos, e só 7\% antepostos. Em termos de peso relativo, o traço semântico [restritivo] favorece a posposição em todos os períodos analisados, menos o século XIV. Veja-se a tabela 4:

Tabela 4: Distribuição da freqüência e do peso relativo dos fatores adjetivos restritivos/qualificativos por século.

\begin{tabular}{lccccccccccccc}
\hline Séc. & Qual. & AN & $\%$ & NA & $\%$ & Peso & Rest. & AN & $\%$ & NA & $\%$ & Peso & Total \\
\hline XIII & $\mathbf{3 0 8}$ & 227 & 74 & 81 & 26 & 0,434 & $\mathbf{2 9}$ & 2 & 6 & 27 & 94 & 0,944 & 337 \\
XIV & $\mathbf{3 5 3}$ & 262 & 75 & 91 & 25 & - & $\mathbf{4 5}$ & 13 & 38 & 32 & 72 & - & 398 \\
XV & $\mathbf{3 6 3}$ & 268 & 74 & 95 & 26 & 0,462 & $\mathbf{3 9}$ & 6 & 15 & 33 & 85 & 0,804 & 402 \\
XX & $\mathbf{1 0 8}$ & 41 & 37 & 67 & 63 & 0,109 & $\mathbf{2 9 0}$ & 8 & 2 & 282 & 98 & 0,684 & 398 \\
\hline Total & $\mathbf{1 1 3 2}$ & $\mathbf{7 9 8}$ & $\mathbf{7 0}$ & $\mathbf{3 3 4}$ & $\mathbf{3 0}$ & - & $\mathbf{4 0 3}$ & $\mathbf{2 9}$ & $\mathbf{7}$ & $\mathbf{3 7 4}$ & $\mathbf{9 3}$ & - & $\mathbf{1 5 3 5}$ \\
\hline
\end{tabular}

Em relação aos traços [primitivo] e [derivado] foi verificado que esse último favorece a posposição, tanto em termos de porcentagem, quanto em termos de peso relativo. Por outro lado, o traço [primitivo] favorece a anteposição de A a N, como apontam os pesos relativos inferiores a 0.5 nos séculos XIII, 0,431; XIV, 0,439 e 0,419. Veja-se a tabela 5: 
Tabela 5: Distribuição da freqüência e do peso relativo dos fatores adjetivos derivados/primitivos por século.

\begin{tabular}{lccccccccccccc}
\hline Séc. & Prim. & AN & $\%$ & NA & $\%$ & Peso & Der. & AN & $\%$ & NA & $\%$ & Peso & Total \\
\hline XIII & $\mathbf{2 1 8}$ & 180 & 83 & 38 & 17 & 0,431 & $\mathbf{1 1 9}$ & 50 & 42 & 69 & 58 & 0,626 & 337 \\
XIV & $\mathbf{3 1 6}$ & 248 & 78 & 68 & 22 & 0,439 & $\mathbf{8 2}$ & 27 & 33 & 55 & 67 & 0,720 & 398 \\
XV & $\mathbf{2 9 2}$ & 236 & 80 & 56 & 20 & 0,419 & $\mathbf{1 1 0}$ & 38 & 35 & 72 & 65 & 0,704 & 402 \\
XX & $\mathbf{1 1 8}$ & 39 & 33 & 79 & 67 & - & $\mathbf{2 8 0}$ & 10 & 4 & 270 & 96 & - & 398 \\
\hline Total & $\mathbf{9 4 4}$ & $\mathbf{7 0 3}$ & $\mathbf{7 4}$ & $\mathbf{2 4 1}$ & $\mathbf{2 6}$ & - & $\mathbf{5 9 1}$ & $\mathbf{3 8 5}$ & $\mathbf{6 5}$ & $\mathbf{2 0 6}$ & $\mathbf{3 5}$ & - & $\mathbf{1 5 3 5}$
\end{tabular}

Foi constatada a atuação da associação de dois fatores, os traços [primitivo] e [gatilho] com relação à anteposição, e foi encontrada uma média de 43\% de associação entre eles; ou seja, do total de itens antepostos, 43\% são ao mesmo tempo primitivos e gatilhos, o que demonstra uma força de associação entre esses fatores. Veja-se a tabela 6:

Tabela 6: Distribuição total da classe dos adjetivos primitivos/gatilhos/antepostos por século.

\begin{tabular}{cccc}
\hline Século & Primitivos & Primitivos/Gatilhos/ AN & $\%$ \\
\hline XIII & 218 & 99 & 45 \\
XIV & 316 & 158 & 50 \\
XV & 292 & 148 & 51 \\
XX & 118 & 8 & 7 \\
\hline Total & $\mathbf{9 4 4}$ & $\mathbf{4 1 3}$ & 43 \\
\hline
\end{tabular}

Por outro lado, foi constatada também a associação de dois outros fatores, os adjetivos [derivado] e [não-gatilho] em relação à posposição, sendo ainda encontrada uma média de 78\% de associação entre eles. No século XX, 96\% do total de itens pospostos aos substantivos são, ao mesmo tempo, [derivado] e [não-gatilho], o que demonstra uma forte relação de combinação entre esses fatores. Vejase a tabela 7: 
Tabela 7: Distribuição total da classe dos adjetivos derivados/classe o/pospostos por século.

\begin{tabular}{cccc}
\hline Século & Derivados & Derivados/Classe O/ NA & $\%$ \\
\hline XIII & 119 & 69 & 57 \\
XIV & 82 & 54 & 65 \\
XV & 110 & 69 & 63 \\
XX & 280 & 270 & 96 \\
\hline Total & $\mathbf{5 9 1}$ & $\mathbf{4 6 2}$ & 78 \\
\hline
\end{tabular}

Em relação aos traços [concreto] e [abstrato] dos substantivos, foi observado, em termos de peso relativo, que o primeiro, o qual favorecia a posposição dos adjetivos nos séculos XIV e XV, passa a desfavorecê-la no século XX. O traço [abstrato] que, por outro lado, favorecia a anteposição nos séculos XIV e XV, passa a favorecê-la no século XX, em $0,874^{2}$.

Em relação aos traços [animado] e [inanimado] foi verificado, em termos de peso relativo, que o primeiro está associado à anteposição de adjetivos no período medieval, e no período contemporâneo sua ocorrência diminui. Apenas 11\% dos animados do século XX são antepostos, sendo que os animados correspondem a apenas 13\% do total de ocorrências desse século, e os inanimados, 87\%. O traço [inanimado] está associado à posposição de adjetivos no período contemporâneo, entretanto, a análise desses fatores só foi relevante para o século XIII, que considerou o fator [inanimado] favorecedor da anteposição em 0.416, e o [animado] seu desfavorecedor em $0,652^{3}$.

\section{ANÁLISE DOS RESULTADOS}

No intuito de traçar uma correspondência entre os fatores, pude verificar, através das análises quantitativas, dois conjuntos de traços semânticos inerentes, a meu ver, a duas classes distintas de adjetivos, que serão denominadas de Adjetivos Qualificativos e de Adjetivos Restritivos. Veja-se seus traços semânticos gerais na tabela 8: 
Tabela 8: Descrição das Classes dos Adjetivos

Qualificativos e Adjetivos Restritivos

\begin{tabular}{c|c|c|c|c}
\hline Aspectos & Adjetivos Qualificativos & Peso & Adjetivos Restritivos & Peso \\
\hline Ordem & Anteposição / AN & 0 & Posposição / NA & 1 \\
Traços $A d j$. & Qualificativo & 0,335 & Restritivos & 0,810 \\
Traços $A d j$. & Primitivo & 0,429 & Derivado & 0,683 \\
Traços $A d j$. & Gatilho & 0,243 & Não-gatilho & 0,574 \\
Traços Subst. & Concreto & 0,445 & Abstrato & 0,874 \\
Intensificação & Passível de intensificação & - & Pouco passível & - \\
Período/ & Período Medieval & - & Período Contemporâneo & - \\
Tendência & & & & \\
\hline
\end{tabular}

A tabela 8 acima indica que, quando a ordem é AN, existirá uma grande possibilidade de um conjunto de fatores estarem associados, formando um continuum semântico. Ou seja, quando a ordem é AN, traços semânticos dos adjetivos como [primitivo], [qualificativo], [gatilho] e traços semânticos do substantivo como [animado], [concreto], podem estar associados entre si, formando um conjunto de fatores que interagem entre si, o que também, como mostra o quadro, ocorre para a classe dos Adjetivos Restritivos. Isso se dá porque, quando a ordenação dos constituintes é NA, traços semânticos dos adjetivos como [derivado], [restritivo], [não-gatilho] e traços semânticos do substantivo como [inanimado], [abstrato] interagem, de modo a formar um conjunto contínuo e interdependente de traços, ou seja, uma classe.

Os valores do peso relativo nessa tabela foram aferidos a partir de uma média geral que considerou todos os períodos analisados para os quais o fator foi relevante, sendo que, como os traços [concreto] e [abstrato], [animado] e [inanimado] apresentaram um comportamento diferente para cada século, mantive os valores do século XX para o primeiro, e do século XIII para o último, o que causa aparente contradição.

Os traços foram classificados considerando-se também as porcentagens, porque nenhum dos fatores teve o peso relativo 
relevante para todos os períodos analisados, o que explica o fato do traço [animado], que apesar de favorecer a posposição no século XX, a desfavorecia, em termos percentuais, no período medieval, do qual não possuo os dados do peso relativo.

Após a apresentação dos resultados e da análise quantitativa, passo às conclusões gerais, desenvolvidas a partir das relações estabelecidas entre os pressupostos teóricos e os resultados da análise quantitativa.

\section{CONCLUSÕES}

A partir dos resultados apresentados nas seções anteriores, pode ser afirmada, em termos quantitativos, a mudança de ordenação dos constituintes N e A no sintagma nominal catalão, passando de AN > NA, como mostram as porcentagens apresentadas no gráfico 1 abaixo:

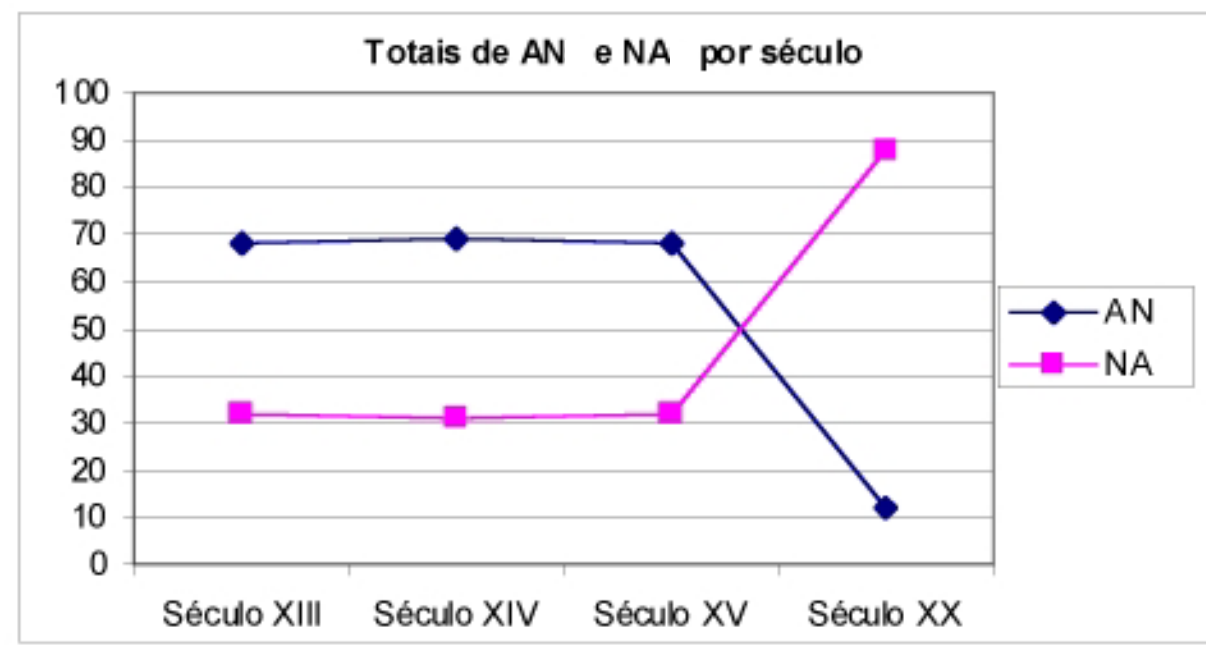

Gráfico 1

Curva do total de SN AN e NA por século. 
Como nos indica o gráfico, as porcentagens de 32\%, 31\% e 32\% respectivamente para os séculos XIII, XIV e XV de ocorrências de sintagmas nominais NA, dão lugar a 88\% de ocorrência de NA no século XX. Por outro lado, as porcentagens de 68\%, 69\% e 68\% respectivamente para os séculos XIII, XIV e XV de ocorrências de sintagmas nominais AN, dão lugar a apenas 12\% de ocorrência de AN no século XX. Desse modo, em termos quantitativos, fica clara a mudança de ordenação dos constituintes AN > NA.

Entretanto, os dados quantitativos, ao se restringirem à descrição da mudança, exigem uma explicação teórica que a elucide. Desse modo, em termos tipológicos, a mudança AN > NA do sintagma nominal catalão está associada a um realinhamento tipológico desses constituintes em relação à mudança dos tipos SOV > SVO.

Entretanto, nas línguas do tipo SVO, como afirma o Universal Lingüístico 19, existem duas ordens possíveis em relação a $\mathrm{N}$ e a A: AN NA. No caso das línguas românicas, os sintagmas nominais marcados são aqueles que os adjetivos se antepõem aos substantivos, AN, como descrito por Waugh (1977), que destaca as motivações lingüísticas que podem levar adjetivos a se anteporem aos substantivos.

Comparando-se os dados do catalão com as análises realizadas por Cohen (1986-1990) para o português, e Totaro (1998) para o espanhol, conclui que são comuns para as três línguas as seguintes considerações:

a) A existência do decréscimo da anteposição de adjetivos ao nome ao longo da história das três línguas;

b) A mudança tipológica AN>NA;

c) Essa mudança identificada acompanha a mudança geral da família românica, evidenciando alteração da ordem SOV/ AN/Po correspondente aos elementos mais arcaicos do Latim e Proto-Indo-Europeu, para uma ordem menos harmônica SVO/NA/Pr.

Do ponto de vista qualitativo, conclui que: 
a) Os adjetivos-gatilho bon, notable, belo, noble e grand dominam a anteposição até o século XV, embora outras classes de adjetivos sempre tenham estado presentes em anteposição na língua catalã;

b) A decodificação dos itens gatilho bon, notable, belo, noble e grand dependem de um contexto, como afirma a fórmula de Dixon (1977) para bom, good for $\mathbf{X}$;

c) Um conjunto de traços semânticos está associado ao posicionamento do adjetivo. Ficou constatado, na análise quantitativa, que os traços semânticos em conjunto [primitivo], [gatilho] e [qualificativo] estão associados à anteposição, e, por outro lado, os traços [derivado], [nãogatilho] e [restritivo] estão intimamente relacionados à posposição.

d) A mudança geral AN>NA está ligada ao comportamento dos itens acima referidos, considerados como itens gatilhos da mudança.

\section{NOTAS}

${ }^{1}$ Universal 19: When the general rule is that the descriptive adjective follows, there may be a minority of adjectives, which usually precede, but when the general rule is that descriptive adjectives precede, there are no exceptions.

${ }^{2}$ Cf. LIMA: 2003 p. 125-128, 136.

${ }^{3}$ Cf. LIMA: 2003 p. 121-124, 137.

\section{REFERÊNCIAS BIBLIOGRÁFICAS}

COHEN, M. A. A. M. O posicionamento do adjetivo no sintagma nominal português. Boletim Centro de Estudos Portugueses, ano IX, X, n. 12, jul. 1986/ Dez. 1988, Imprensa Universitária, UFMG: Belo Horizonte.

COHEN, M. A. A. M. Syntactic Change in Portuguese: relative clauses and the position of the adjective noun phrase. 1986/1990. 257 p. Tese (Doutoramento) - Unicamp, Campinas. 
DIXON, R. M. W. Where have all the adjectives gone? Studies in Language 1: 1, 1977.

GREENBERG J. Some universals of grammar with particular reference to the order of meaningful elements. In: GREENBERG, J. ( Ed ). Universals of Language. 1966.

LABOV, W. Principles of linguistic change. Vol 1: Internal Factors. Cambridge: Blackwell, 1994.

LIMA, Bruno F. Z. Análise da ordem dos constituintes adjetivo e substantivo em textos catalães dos séculos XIII,XIV, XV e XX. 2003. 147 p. Dissertação (Mestrado em Estudos Lingüísticos) - Faculdade de Letras da UFMG, Belo Horizonte.

MAURER, Jr. T. H. Gramática do latim vulgar. Rio de Janeiro: Acadêmica, 1968.

TOTARO, J. H. R. Mudança de ordem dos constituintes adjetivo e nome em textos espanbóis dos séculos XIII a XX. 1998. 95 p. Dissertação (Mestrado em Estudos Lingüísticos) - Faculdade de Letras da UFMG, Belo Horizonte.

WAUGH, L. A semantic analysis of word order. Leiden: E. J. Brill, 1977. 